\title{
Blood-Brain Barrier Transport of 1-Aminocyclohexanecarboxylic Acid, a Nonmetabolizable Amino Acid for In Vivo Studies of Brain Transport
}

\author{
Masaki Aoyagi, *Bernard W. Agranoff, †Lee C. Washburn, and Quentin R. Smith \\ Laboratory of Neurosciences, National Institute on Aging, National Institutes of Health, Bethesda, Maryland; \\ ${ }^{*}$ Neuroscience Laboratory, University of Michigan, Ann Arbor, Michigan; and $\dagger$ Medical and Health \\ Sciences Division, Oak Ridge Associated Universities, Oak Ridge, Tennessee, U.S.A.
}

\begin{abstract}
Regional transport of 1-aminocyclohexanecarboxylic acid ( $\mathrm{ACHC}$ ), a nonmetabolizable amino acid, across the blood-brain barrier was studied in pentobarbital-anesthetized rats using an in situ brain perfusion technique. The concentration dependence of influx was best described by a model with a saturable and a nonsaturable component. Best-fit values for the kinetic constants of the frontal cortex equaled $9.7 \times 10^{-4} \mu \mathrm{mol} / \mathrm{s} / \mathrm{g}$ for $V_{\max }, 0.054$ $\mu \mathrm{mol} / \mathrm{ml}$ for $K_{\mathrm{m}}$, and $1.0 \times 10^{-4} \mathrm{ml} / \mathrm{s} / \mathrm{g}$ for $K_{\mathrm{D}}$ in the absence of competing amino acids. Saturable influx could be reduced by $>85 \%$ by either $L$-phenylalanine or 2 -aminobicyclo[2.2.1] heptane-2-carboxylic acid, consistent with transport by the cerebrovascular neutral amino acid trans-
\end{abstract}

port system. The transport $K_{\mathrm{m}}$ for $\mathrm{ACHC}$ was one-fifth that for the more commonly used homologue, 1-aminocyclopentanecarboxylic acid, and was similar to values for several natural amino acids, such as L-methionine, L-isoleucine, and L-tyrosine. The results indicate that ACHC may be a useful probe for in vivo studies of amino acid transport into brain. Key Words: Amino acid-Blood-brain barrier - Transport-Capillary-Brain-Rat. Aoyagi M. et al. Blood-brain barrier transport of 1-aminocyclohexanecarboxylic acid, a nonmetabolizable amino acid for in vivo studies of brain transport. $J$. Neurochem. 50, 1220-1226 (1988).
Amino acids are transported from plasma to brain by specific saturable carriers at the cerebral capillaries of the blood-brain barrier (Oldendorf, 1971; Oldendorf and Szabo, 1976). Regional transport rates can be measured in vivo in humans using positron emission tomography or in experimental animals using quantitative autoradiography. In most studies, labeled forms of natural amino acids, such as L-methionine or L-leucine, have been used (Comar et al., 1981; Mans et al., 1982; Phelps et al., 1985; Bergstrom et al., 1987). However, natural amino acids have limitations in transport studies because subsequent to uptake, they are metabolized and incorporated into proteins. These processes can lead to errors in measured influx rates and prevent accurate determination of efflux rates.

To overcome these limitations, synthetic amino acids have been developed that are neither metabo- lized nor incorporated into proteins. One such amino acid, 1-aminocyclopentanecarboxylic acid (ACPC), has been used extensively to study neutral amino acid (NAA) transport in peripheral tissues (Oxender and Christensen, 1963; Christensen, 1973). ACPC is transported by the NAA carrier at the blood-brain barrier (Pardridge and Oldendorf, 1975). However, the carrier affinity for the amino acid is low, approximately one-tenth that of L-leucine (Smith and Takasato, 1986).

Washburn et al. (1981) have suggested that a homologue based on a cyclohexane rather than a cyclopentane ring, 1-aminocyclohexanecarboxylic acid (ACHC), may have greater affinity than ACPC for the cerebrovascular NAA transport system. ACHC, like ACPC, is neither metabolized nor incorporated into tissue proteins (Christensen and Jones, 1962). We therefore thought it of interest to examine the
Received July 22, 1987 ; revised manuscript received October 29 , 1987; accepted October 30, 1987.

Address correspondence and reprint requests to Dr. Q. R. Smith at Laboratory of Neurosciences, National Institute on Aging, NIH 10/6C103, Bethesda, MD 20892, U.S.A.
Abbreviations used: ACBC, 1 -aminocyclobutanecarboxylic acid; ACHC, 1-aminocyclohexanecarboxylic acid; ACPC, 1-aminocyclopentanecarboxylic acid; $\mathrm{BCH}, 2$-aminobicyclo[2.2.1]heptane-2-carboxylic acid; MeAIB, methylaminoisobutyric acid; NAA, neutral amino acid. 
transport kinetics of $\mathrm{ACHC}$ at the blood-brain barrier to determine whether it would indeed be a preferable tracer for in vivo studies of cerebrovascular NAA transport. If so, it may prove useful for studies in humans using positron emission tomography (Comar et al., 1981; Bergstrom et al., 1987).

\section{MATERIALS AND METHODS}

\section{Materials}

[carboxyl $\left.{ }^{14} \mathrm{C}\right] \mathrm{ACHC}$ (sp act $377 \mu \mathrm{Ci} / \mathrm{mg}$ ) was prepared from $\mathrm{K}^{14} \mathrm{CN}$ and cyclohexanone using a modified Bucherer-Strecker synthesis followed by purification with ionexchange chromatography (Hayes et al., 1978; Washburn et al., 1979). Radiochemical purity was verified by TLC on silica gel with butanol/water/acetic acid (100:10:5 vol/vol) as solvent. Unlabeled $\mathrm{ACHC}$ and 1-aminocyclobutanecarboxylic acid (ACBC) were synthesized and purified as previously described by Connors and Ross (1960). Other amino acids were obtained from Sigma Chemical (St. Louis, MO, U.S.A.). $\left[N-m e t h y l-{ }^{3} \mathrm{H}\right]$ Diazepam and $\left[\right.$ methoxy- $\left.{ }^{3} \mathrm{H}\right]$ inulin were purchased from AmershamSearle (Arlington Heights, IL, U.S.A.) and New England Nuclear (Boston, MA, U.S.A.), respectively.

\section{Determination of $\mathrm{ACHC}$ influx}

$\left[{ }^{14} \mathrm{C}\right] \mathrm{ACHC}$ transport across the blood-brain barrier was measured with the in situ brain perfusion technique of Takasato et al. (1984). This procedure allows accurate measurements of influx and complete control of perfusate composition (Smith et al., 1985; Momma et al., 1987).

All experiments used adult male rats (Sprague-Dawley strain), weighing $240-350 \mathrm{~g}$, that were anesthetized with sodium pentobarbital $(40 \mathrm{mg} / \mathrm{kg}$, i.p.). In each rat, the right external carotid artery was catheterized for retrograde infusion, and the right pterygopalatine, occipital, and superior thyroid arteries were coagulated and cut. Rectal temperature was maintained at $37 \pm 0.5^{\circ} \mathrm{C}$ with a heat lamp.

To start the perfusion, the right common carotid artery was ligated, and then perfusion fluid was infused into the external carotid artery at $5 \mathrm{ml} / \mathrm{min}$ with a pump. In most experiments, the perfusate consisted of $\mathrm{HCO}_{3}$-buffered physiological saline $\left(\mathrm{pH} 7.4,37^{\circ} \mathrm{C}\right.$; Momma et al., 1987) that contained $0.08 \mu \mathrm{Ci} / \mathrm{ml}$ of $\left[{ }^{14} \mathrm{C}\right] \mathrm{ACHC}, 0.58 \mu \mathrm{Ci} / \mathrm{ml}$ of $\left[{ }^{3} \mathrm{H}\right]$ inulin to measure intravascular volume, and $0-10$ $\mu \mathrm{mol} / \mathrm{ml}$ of unlabeled amino acid. However, in some experiments a plasma perfusate was used to determine $\left[{ }^{14} \mathrm{C}\right]$ $\mathrm{ACHC}$ uptake in the presence of normal physiological concentrations of competing amino acids. Plasma for perfusion was obtained from heparinized donor rats on the morning of the experiment. Cerebral perfusion fluid flow was measured in separate animals as described by Takasato et al. (1984).

Twenty seconds after the start of the perfusion, the animal was killed by decapitation and the pump was turned off. Following removal of the brain from the skull, samples from six brain regions were dissected from the right cerebral hemisphere, as previously described by Smith et al. (1985). The tissue samples along with a $20-\mu 1$ aliquot of perfusion fluid were weighed, digested in $1 M$ piperidine, and prepared for counting by addition of scintillation cocktail. Dual-label counting was performed with a Beckman LS6800 liquid scintillation counter (Beckman Instruments, Fullerton, CA, U.S.A.). Amino acid concentrations in plasma were determined by HPLC (Smith et al., 1985).

\section{Calculations}

Unidirectional ACHC influx $\left(J_{\text {in }}\right)$ into brain was calculated with the following equation

$$
J_{\text {in }}=\left[q_{\mathrm{br}}^{*} / C_{\mathrm{pr}}^{*} T\right] C_{\mathrm{pr}}
$$

where $q_{\mathrm{br}}^{*}=$ parenchymal brain content of $\left[{ }^{14} \mathrm{C}\right] \mathrm{ACHC}$ at the time of death, $C_{\mathrm{pf}}^{*}=$ perfusate concentration of $\left[{ }^{14} \mathrm{C}\right]-$ ACHC, $C_{\mathrm{pf}}=$ perfusate concentration of ACHC, and $T$ $=$ net perfusion time (Smith et al., 1985). To ensure unidirectional uptake kinetics, perfusion time was limited to $20 \mathrm{~s}$ in all experiments (Momma et al., 1987). The value for $q_{\mathrm{br}}^{*}$ was obtained from the measured brain content of $\left[{ }^{14} \mathrm{C}\right]-$ ACHC $\left(q_{\mathrm{tot}}^{*}\right)$ by subtraction of residual intravascular tracer as

$$
q_{\mathrm{br}}^{*}=q_{\mathrm{tot}}^{*}-V_{\mathrm{v}} C_{\mathrm{pf}}^{*}
$$

where $V_{\mathrm{v}}$ is the brain vascular volume. $V_{\mathrm{v}}$ was measured with $\left[{ }^{3} \mathrm{H}\right]$ inulin and averaged $0.76 \pm 0.03 \times 10^{-2} \mathrm{ml} / \mathrm{g}$ (mean \pm SEM, $\mathrm{n}=26$ ) in the six brain regions. The value for $q_{\mathrm{br}}^{*}$ was not corrected for residual tracer in the brain capillary endothelium. $\left[{ }^{14} \mathrm{C}\right] \mathrm{ACHC}$ influx was calculated as $q_{\mathrm{br}}^{*} / T$.

The concentration dependence of amino acid transport across the blood-brain barrier can be described by a model with a saturable and a nonsaturable component (Pardridge, 1983). In the absence of competing amino acids, $J_{\text {in }}$ is given as

$$
J_{\text {in }}=\frac{V_{\text {max }} \bar{C}_{\text {cap }}}{K_{\mathrm{m}}+\bar{C}_{\text {cap }}}+K_{d} \bar{C}_{\text {cap }}
$$

where $V_{\max }=$ maximal transport capacity of the saturable component, $K_{\mathrm{m}}=$ half-saturation concentration, $K_{\mathrm{D}}$ $=$ constant of nonsaturable diffusion, and $\bar{C}_{\text {cap }}=$ mean capillary concentration of amino acid. For $\mathrm{ACHC}, \bar{C}_{\text {cap }}$ was calculated as

$$
\bar{C}_{\text {cap }}=K_{\text {in }} C_{\text {pf }} /\left[-F \ln \left(1-K_{\text {in }} / F\right)\right]
$$

where $K_{\text {in }}$ is the unidirectional transfer constant for $\mathrm{ACHC}$ uptake into brain $\left(K_{\mathrm{in}}=q_{\mathrm{br}}^{*} / C_{\mathrm{pf}}^{*} T\right)$ and $F=$ cerebral perfusion fluid flow. $F$ was measured in separate animals from the uptake of $\left[{ }^{3} \mathrm{H}\right]$ diazepam (Takasato et al., 1984) and ranged from $8.9 \pm 0.4 \times 10^{-2} \mathrm{ml} / \mathrm{s} / \mathrm{g}$ (mean $\pm \mathrm{SEM}, \mathrm{n}=9$ ) in the parietal cortex to $4.6 \pm 0.3 \times 10^{-2} \mathrm{ml} / \mathrm{s} / \mathrm{g}$ in the caudate nucleus. Because of the rapid flow rate with the perfusion technique, the difference between $\bar{C}_{\mathrm{cap}}$ and $C_{\mathrm{pf}}$ was small, averaging only $2 \%$ overall with a maximal value of $9 \%$. Values of $V_{\max }, K_{\mathrm{m}}$, and $K_{\mathrm{D}}$ were obtained from the weighted least-squares fit of Eq. 3 to the saline perfusion data, as previously described by Smith et al. (1985) and Momma et al. (1987).

With competing amino acids in the perfusate, the concentration dependence of $\mathrm{ACHC}$ influx can be described by an equation similar to Eq. 3 but with $K_{\mathrm{m}}(\mathrm{app})$ in place of $K_{\mathrm{m}} \cdot K_{\mathrm{m}}(\mathrm{app})$ is defined as (Pardridge, 1977)

$$
K_{\mathrm{m}}(\operatorname{app})=K_{\mathrm{m}}\left[1+\sum\left(\bar{C}_{\mathrm{cap}(\mathrm{i})} / K_{\mathrm{i}}\right)\right]
$$

where $\bar{C}_{\text {cap (i) }}=$ mean capillary concentration of each competing amino acid and $K_{\mathrm{i}}=$ respective inhibition constant for that amino acid. $K_{\mathrm{m}}(\mathrm{app})$ was calculated from the ACHC influx from plasma using values of $V_{\max }$ and $K_{\mathrm{D}}$ from the saline perfusion data.

$K_{\mathrm{i}}$ values for individual amino acids were determined from their inhibition of ACHC influx into brain. At tracer 
ACHC concentration, the ratio of $J_{\text {in }}$ in the absence of competing amino acid $\left[\left(J_{\mathrm{in}}\right)_{\mathrm{o}}\right]$ to that in the presence of competing amino acid $\left[\left(J_{\text {in }}\right)_{\mathrm{i}}\right]$ is given as

$$
\left(J_{\text {in }}\right)_{\mathrm{o}} /\left(J_{\mathrm{in}}\right)_{\mathrm{i}}=1+\bar{C}_{\text {cap }(\mathrm{i})} / K_{\mathrm{i}}
$$

$K_{\mathrm{i}}$ was calculated from the $\left(J_{\text {in }}\right)_{\mathrm{o}} /\left(J_{\text {in }}\right)_{\mathrm{i}}$ ratio assuming $\bar{C}_{\text {cap }(\mathrm{i})}$ equals the perfusate concentration of competing amino acid.

\section{Statistics}

All values are means \pm SEM, unless otherwise noted. Differences between means were analyzed for statistical significance at the $\mathrm{p}<0.05$ level using one-way analysis of variance and the Bonferroni multiple comparison test (Miller, 1966).

\section{RESULTS}

\section{Saline perfusion}

Figure 1 illustrates the relationship between $\mathrm{ACHC}$ influx and concentration for one brain region, the frontal cerebral cortex. For this experiment, ACHC was the only amino acid in the saline perfusate. The concentration dependence of influx could be described by a model with a saturable and a nonsaturable component. At concentrations $<0.3 \mu \mathrm{mol} / \mathrm{ml}$, the nonsaturable component contributed minimally $(<10 \%)$ to total influx.

$V_{\max }, K_{\mathrm{m}}$, and $K_{\mathrm{D}}$ values were calculated by fitting Eq. 3 to the ACHC influx data using weighted nonlinear least squares. Best-fit values of the parameters are listed in Table 1. These values were calculated using the influx data over the entire concentration range from 0.0001 to $10 \mu \mathrm{mol} / \mathrm{ml}$. To determine whether the fit of the nonsaturable component $\left(K_{\mathrm{D}}\right)$ markedly affected the calculated values for $V_{\max }$ or $K_{\mathrm{m}}$, the transport constants were also calculated using only the flux data at low concentrations ( $\leq 1$ $\mu \mathrm{mol} / \mathrm{ml}$ ) where the contribution of the nonsaturable component could be ignored $\left(K_{\mathrm{D}}=0\right)$. Best-fit values for $V_{\max }$ and $K_{\mathrm{m}}$ using this alternate analysis were within $15 \%$ and did not differ significantly from corresponding values in Table 1 . For example, $V_{\max }$ and $K_{\mathrm{m}}$ equaled $10.8 \pm 1.2 \times 10^{-4} \mu \mathrm{mol} / \mathrm{s} / \mathrm{g}$ and 0.062 $\pm 0.011 \mu \mathrm{mol} / \mathrm{ml}(\mathrm{n}=20)$, respectively, in the frontal cortex.
There were no significant regional differences in $K_{\mathrm{m}}$ or $K_{\mathrm{D}}$ among the six brain regions (Table 1). However, $V_{\max }$ was significantly greater in the frontal and parietal cortices than in the hippocampus, caudate nucleus, or thalamus-hypothalamus.

ACHC influx into brain was inhibited competitively by L-phenylalanine. The concentration dependence of inhibition is shown in Fig. 2 for the frontal cortex. Influx was reduced $>85 \%$ at a perfusate $L$ phenylalanine concentration of $0.1 \mu \mathrm{mol} / \mathrm{ml}$. The calculated $K_{\mathrm{i}}$ equaled $0.012 \pm 0.001 \mu \mathrm{mol} / \mathrm{ml}$ (mean $\pm \mathrm{SEM}, \mathrm{n}=12$ ) and did not differ from that in the other five brain regions.

Table 2 summarizes the effects of various amino acids on $\left[{ }^{14} \mathrm{C}\right] \mathrm{ACHC}$ uptake into brain. 2-Aminobicyclo[2.2.1] heptanecarboxylic acid $(\mathrm{BCH})$, the model substrate for the $\mathrm{L}$ system (Christensen, 1973), reduced $\left[{ }^{14} \mathrm{C}\right] \mathrm{ACHC}$ influx by $\sim 90 \%$ at a concentration of $1 \mu \mathrm{mol} / \mathrm{ml}$. In contrast, neither methylaminoisobutyric acid (MeAIB), the model substrate for the A system, nor L-lysine, a substrate for the cationic $\left(\mathrm{y}^{+}\right)$amino acid transport system, produced significant inhibition of $\left[{ }^{14} \mathrm{C}\right] \mathrm{ACHC}$ influx. $\mathrm{ACPC}$ and $\mathrm{ACBC}$, the smaller homologues of $\mathrm{ACHC}$, produced less inhibition of $\left[{ }^{14} \mathrm{C}\right] \mathrm{ACHC}$ influx at $0.3 \mu \mathrm{mol} / \mathrm{ml}$ than $\mathrm{ACHC}$ at the same concentration. Calculated $K_{\mathrm{i}}$ values for $\mathrm{ACPC}$ and $\mathrm{ACBC}$ were, on average, $\sim 5$ and $\sim 35$ times greater, respectively, than the $K_{\mathrm{m}}$ for ACHC.

\section{Plasma perfusion}

Regional ACHC influx from plasma was 8.8 $\pm 0.5 \%(n=5)$ of that measured at the same concentration using saline perfusate that did not contain competing amino acids. $K_{\text {in }}$ from plasma ranged from $13.1 \pm 0.9 \times 10^{-4} \mathrm{ml} / \mathrm{s} / \mathrm{g}$ in the frontal cortex to 10.7 $\pm 0.9 \times 10^{-4} \mathrm{ml} / \mathrm{s} / \mathrm{g}$ in the hippocampus. Competition for transport increased the mean regional $K_{\mathrm{m}}$ (app) by $\sim 14$-fold from $0.053 \pm 0.002$ to 0.72 $\pm 0.02 \mu \mathrm{mol} / \mathrm{ml}$. $K_{\mathrm{m}}(\mathrm{app})$ did not differ significantly among the six brain regions.

Table 3 compares regional ACHC influx rates as measured during plasma perfusion with values predicted using Eqs. 3 and 5 and the measured NAA
FIG. 1. Unidirectional $A C H C$ influx into frontal cortex as a function of $A C H C$ concentration of saline perfusate. Left: Influx versus concentration from 0 to $0.3 \mu \mathrm{mol} / \mathrm{ml}$. Right: Influx versus concentration from 0 to $10 \mu \mathrm{mol} / \mathrm{ml}$. Data are means \pm SEM (bars) values for three or four animals. The curves represent total, saturable, and nonsaturable influxes as predicted by Eq. 3 where $V_{\max }=9.7 \times 10^{-4} \mu \mathrm{mol} / \mathrm{s} /$ $\mathrm{g}, K_{\mathrm{m}}=0.054 \mu \mathrm{mol} / \mathrm{ml}$, and $K_{\mathrm{D}}=1.0 \times 10^{-4} \mathrm{ml} / \mathrm{s} / \mathrm{g}$.
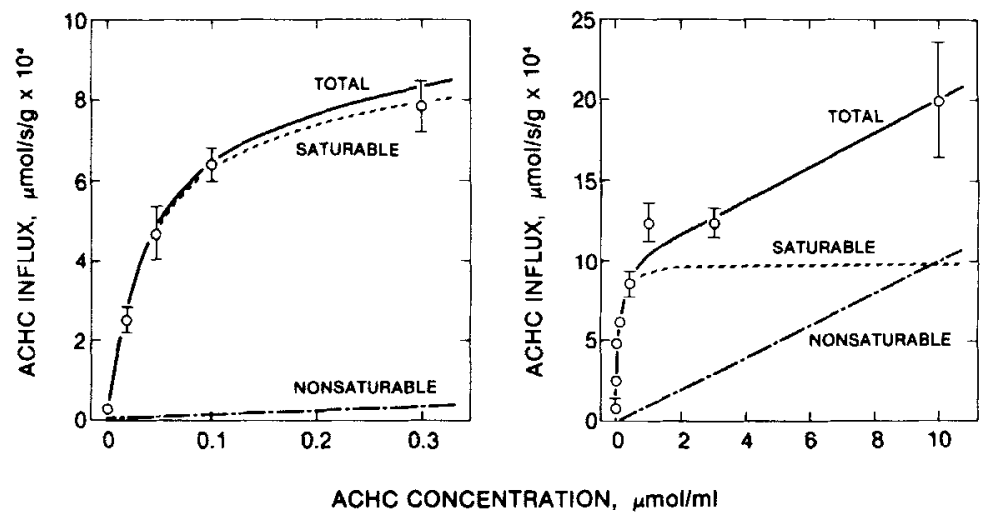
TABLE 1. $\mathrm{V}_{\max }, \mathbf{K}_{m}$, and $\mathbf{K}_{D}$ for cerebrovascular transport of $A C H C$ from saline perfusate to brain

\begin{tabular}{lccc}
\hline \multicolumn{1}{c}{ Brain region } & $\begin{array}{c}V_{\max } \\
\left(\mu \mathrm{mol} / \mathrm{s} / \mathrm{g} \times 10^{4}\right)\end{array}$ & $\begin{array}{c}K_{\mathrm{m}} \\
(\mu \mathrm{mol} / \mathrm{ml})\end{array}$ & $\begin{array}{c}K_{\mathrm{D}} \\
\left(\mathrm{ml} / \mathrm{s} / \mathrm{g} \times 10^{4}\right)\end{array}$ \\
\hline Frontal cortex & $9.7 \pm 0.7$ & $0.054 \pm 0.005$ & $1.0 \pm 0.3$ \\
Parietal cortex & $8.9 \pm 0.6$ & $0.048 \pm 0.004$ & $1.6 \pm 0.3$ \\
Occipital cortex & $7.7 \pm 0.6$ & $0.057 \pm 0.008$ & $1.1 \pm 0.4$ \\
Hippocampus & $6.6 \pm 0.9^{a}$ & $0.056 \pm 0.009$ & $1.1 \pm 0.5$ \\
Caudate nucleus & $6.5 \pm 0.7^{a}$ & $0.049 \pm 0.007$ & $1.5 \pm 0.3$ \\
Thalamus-hypothalamus & $6.5 \pm 0.7^{a}$ & $0.054 \pm 0.008$ & $1.6 \pm 0.3$ \\
\hline
\end{tabular}

Values are means \pm SEM for 26 rats.

${ }^{a}$ Differs significantly from mean value for frontal cortex.

concentrations of plasma perfusate. $V_{\max }, K_{\mathrm{m}}$, and $K_{\mathrm{D}}$ values for predicted influx were obtained from Table 1, whereas $K_{\mathrm{i}}$ values for competing NAAs were taken from Smith et al. (1987), assuming $K_{\mathrm{i}} \cong K_{\mathrm{m}}$. Predicted influx rates using this analysis were within $30 \%$ of measured values in each of the six brain regions. The differences were not statistically significant $(p>0.05)$.

\section{DISCUSSION}

This study demonstrates that the nonmetabolizable amino acid, ACHC, is transported across the blood-brain barrier by the cerebrovascular NAA system. The transport $K_{\mathrm{m}}$ for ACHC is one-fifth that of the more commonly used homologue, ACPC, and is comparable to values for several natural amino acids, such as L-methionine, L-isoleucine, and L-tyrosine. The results suggest that $\mathrm{ACHC}$ may be a useful tracer for in vivo studies of amino acid transport into brain.

Neutral amino acids are transported into brain by a common carrier that is located at the cerebral capillaries of the blood-brain barrier (Oldendorf, 1971; Hawkins et al., 1982). This transport system facilitates the brain uptake of 14 plasma NAAs and has greatest affinity for amino acids with large aliphatic or aromatic side chains, such as L-phenylalanine (Oldendorf and Szabo, 1976; Smith et al., 1987). Trans- port is sodium independent and inhibited competitively by $\mathrm{BCH}$, the defining substrate for the $\mathrm{L}$ system of Christensen (Wade and Katzman, 1975; Momma et al., 1987). Saturable ACHC transport across the blood-brain barrier can be localized to the cerebrovascular NAA carrier, since both BCH and L-phenylalanine inhibit $>90 \%$ of brain ACHC uptake. Significant contributions from other transport systems were not detected, as neither MeAIB nor L-lysine significantly reduced $\mathrm{ACHC}$ influx into brain.

Regional $V_{\max }$ values for cerebrovascular $\mathrm{ACHC}$ transport are comparable to values for other NAAs, such as L-phenylalanine and L-leucine (Smith et al., 1985; Momma et al., 1987), consistent with transport by the same carrier mechanism. The greater $V_{\max }$ in the frontal and parietal cortex than in the other brain regions is consistent with the greater vascularity and thus capillary surface area of the cortex (Hawkins et al., 1982). Similar regional differences were observed in both $F$ and $V_{\mathrm{v}}$ (Smith et al., 1985).

There were no significant regional differences in $K_{\mathrm{m}}$ for saturable ACHC transport. The mean value for the six brain regions equaled $0.053 \mu \mathrm{mol} / \mathrm{ml}$, which is greater than that for L-phenylalanine $(0.011$ $\mu \mathrm{mol} / \mathrm{ml}$ ), the plasma amino acid with greatest affinity for the transport system, but comparable to values for several other plasma amino acids, such as L-methionine $(0.040 \mu \mathrm{mol} / \mathrm{ml})$, L-isoleucine $(0.056 \mu \mathrm{mol} /$

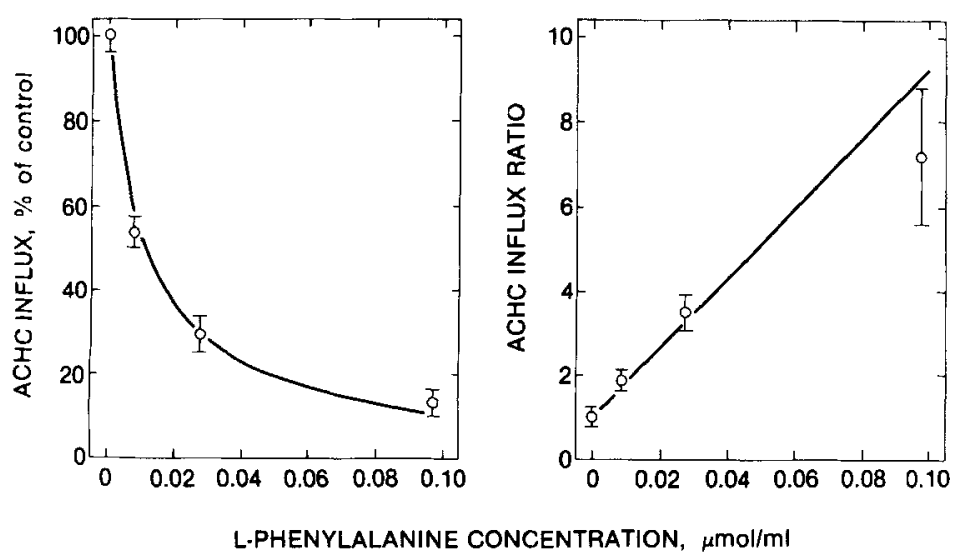

FIG. 2. Inhibition of $A C H C$ influx into frontal cortex as a function of perfusate $L$-phenylalanine concentration. Left: $A C H C$ influx versus $L$-phenylalanine concentration. Right: $A C H C$ influx ratio $\left[\left(J_{i n}\right)_{0} /\left(J_{i n}\right)_{i}\right]$ versus Lphenylalanine concentration. Each point represents a mean for three animals. The lines illustrate the predicted influx and influx ratio, respectively, assuming $K_{i}$ $=0.012 \mu \mathrm{mol} / \mathrm{ml}$. 
TABLE 2. Effects of various amino acids on $l^{14} \mathrm{CJACHC}$ influx into frontal cortex from saline perfusate

\begin{tabular}{lccc}
\hline $\begin{array}{c}\text { Amino } \\
\text { acid }\end{array}$ & $\begin{array}{c}\text { Concentration } \\
(\mu \mathrm{mol} / \mathrm{ml})\end{array}$ & $\begin{array}{c}{\left[^{14} \mathrm{C}\right] \mathrm{ACHC} \text { influx }} \\
(\% \text { of control })\end{array}$ & $\begin{array}{c}K_{\mathrm{i}} \\
(\mu \mathrm{mol} / \mathrm{ml})\end{array}$ \\
\hline BCH & 1.0 & $9 \pm 1^{a}$ & $0.099 \pm 0.007$ \\
MeAIB & 1.0 & $102 \pm 7$ & - \\
L-Lysine & 1.0 & $100 \pm 6$ & - \\
ACHC & 0.3 & $15 \pm 2^{a}$ & $0.051 \pm 0.005$ \\
ACPC & 0.3 & $44 \pm 4^{a}$ & $0.245 \pm 0.042$ \\
ACBC & 0.3 & $100 \pm 8$ & - \\
& 10.0 & $16 \pm 2^{a}$ & $1.89 \pm 0.25$ \\
\hline
\end{tabular}

Values are means \pm SEM for three or four animals.

${ }^{a}$ Differs significantly from 100 .

$\mathrm{ml}$ ), and L-tyrosine $(0.064 \mu \mathrm{mol} / \mathrm{ml})$ (Smith et al., 1987). The value is approximately one-fifth that of ACPC, as determined from either self-saturation $(0.29 \mu \mathrm{mol} / \mathrm{ml} ;$ Smith and Takasato, 1986) or inhibition $(0.25 \mu \mathrm{mol} / \mathrm{ml})$ studies, and is approximately $1 / 35$ that of ACBC. The similarity between $K_{\mathrm{m}}$ and $K_{\mathrm{i}}$ values for cerebrovascular NAA transport has been previously observed by Pardridge (1977) and Smith et al. (1987).

The differences in $K_{\mathrm{m}}$ between $\mathrm{ACHC}, \mathrm{ACPC}$, and ACBC are consistent with the known properties of the cerebrovascular NAA carrier. The transport $K_{\mathrm{m}}$ for an $\alpha$-NAA at the blood-brain barrier is determined in large part by side chain hydrophobicity. For the 14 plasma NAAs with measurable affinity for the carrier, there is a linear relationship between $1 / K_{\mathrm{m}}$ and hydrophobicity as measured by the octanol/ water partition coefficient (Smith et al., 1987). The three nonmetabolizable amino acids differ not only in ring size but in ring hydrophobicity. Each additional $\mathrm{CH}_{2}$ group increases the partition coefficient by approximately threefold (Leo et al., 1971). Calculated $K_{\mathrm{m}}$ values from partition coefficients and the empirical relationship between the partition coefficient and $1 / K_{\mathrm{m}}$ predict a fivefold difference in $K_{\mathrm{m}}$ between $\mathrm{ACHC}$ and $\mathrm{ACPC}$ and a 20 -fold difference between $A C H C$ and $A C B C$. The similarity between the predicted and the measured differences suggests that the measured $K_{\mathrm{m}}$ differences can be explained primarily in terms of side chain hydrophobicity. Although further increase in ring size beyond that of $\mathrm{ACHC}$ would be expected to produce compounds with lower $K_{\mathrm{m}}$, this may not occur because of steric limitations in the binding site (Washburn et al., 1981).

DeFeudis (1986) has suggested that published $K_{\mathrm{m}}$ values for cerebrovascular NAA transport as measured with the brain perfusion technique, as well as other methods, may be in error because influx values were not corrected for NAA metabolism in brain endothelial cells. If the rate of metabolism in the endothelial cell were significant compared to the rate of transport, then simple measurements of brain tracer uptake would overestimate NAA flux from plasma to brain extracellular fluid. To support this hypothesis he pointed out that the $K_{\mathrm{m}}$ for the nonmetabolizable NAA, ACPC, differed markedly from that for metabolizable NAAs, such as L-leucine and L-isoleucine. However, our results with ACHC would appear to indicate that endothelial cell metabolism does not lead to large errors in the measurement of transport $K_{\mathrm{m}}$. Our value for the $K_{\mathrm{m}}$ of ACHC is comparable to that of L-leucine and L-isoleucine. The three NAAs have similar octanol/water partition coefficients (Leo et al., 1971). In addition, our value for the $K_{\mathrm{j}}$ of Lphenylalanine, as measured from the inhibition of $\left[{ }^{14} \mathrm{C}\right] \mathrm{ACHC}$ influx into brain, agrees well with the reported $K_{\mathrm{m}}$ for L-phenylalanine transport (Momma et al., 1987). The differences in $K_{\mathrm{m}}$ between ACPC and L-leucine and L-isoleucine result most likely from differences in side chain hydrophobicity (Leo et al., 1971; Smith et al., 1987) and not from endothelial metabolism artifacts.

ACHC influx from plasma is only $\sim 9 \%$ of that from saline at the same concentration because of transport inhibition by competing amino acids. Cerebrovascular NAA transport is sensitive to competition effects because 14 plasma NAAs share the same transport system and because $K_{\mathrm{m}}$ values are low, comparable to plasma concentrations (Pardridge, 1977; Smith et al., 1987). As a result, the transport system is nearly $(\sim 96 \%)$ saturated with amino acids as a group, and each NAA must compete for available transport sites. Competition increases the $K_{\mathrm{m}}(\mathrm{app}) 10$ to 25 -fold (Smith et al., 1985, 1987) and makes the saturable influx of each NAA dependent on the plasma concentrations of all competing amino acids.

In addition to $\mathrm{ACHC}$ transport by the cerebrovascular NAA carrier, there is a small nonsaturable com-

TABLE 3. Regional $A C H C$ influx into rat brain: comparison of predicted and measured values

\begin{tabular}{lccc}
\hline & \multicolumn{2}{c}{$\begin{array}{c}\text { ACHC influx } \\
\left(\mu \mathrm{mol} / \mathrm{s} / \mathrm{g} \times 10^{6}\right)\end{array}$} & $\begin{array}{c}\text { Percent } \\
\text { Brain region }\end{array}$ \\
\cline { 2 - 3 } \multicolumn{1}{c}{ Measured } & Predicted & \\
\hline Frontal cortex & $3.8 \pm 0.4$ & $3.3 \pm 0.4$ & -13 \\
Parietal cortex & $3.8 \pm 0.4$ & $3.6 \pm 0.3$ & -5 \\
Occipital cortex & $3.7 \pm 0.5$ & $2.6 \pm 0.3$ & -30 \\
Hippocampus & $3.1 \pm 0.3$ & $2.3 \pm 0.2$ & -26 \\
Caudate nucleus & $3.4 \pm 0.4$ & $2.7 \pm 0.3$ & -21 \\
Thalamus-hypothalamus & $3.4 \pm 0.4$ & $2.5 \pm 0.2$ & -26 \\
\hline
\end{tabular}

Values are means \pm SEM for five animals. Measured influx was obtained by brain perfusion with rat plasma containing 0.00289 $\pm 0.00015 \mu \mathrm{mol} / \mathrm{ml} \mathrm{ACHC}$. Predicted influx was calculated using Eqs. 3 and 5. Values of $V_{\max }, K_{\mathrm{m}}$, and $K_{\mathrm{D}}$ for ACHC were obtained from Table 1 and values for $K_{i}$ for competing NAAs were taken from Smith et al. (1987). Amino acid concentrations of plasma perfusate equaled (in $\mu \mathrm{mol} / \mathrm{ml}$ ): Phe, $0.057 \pm 0.006$; Trp (free), $0.016 \pm 0.003 ;$ Leu, $0.121 \pm 0.014 ;$ Met, $0.053 \pm 0.007$; lle, 0.064 $\pm 0.007 ;$ Tyr, $0.055 \pm 0.006 ;$ His, $0.079 \pm 0.009 ;$ Val, 0.114 $\pm 0.012 ; \mathrm{Thr}, 0.215 \pm 0.034 ; \mathrm{Gln}, 0.458 \pm 0.053 ;$ Asn, 0.036 $\pm 0.003 ;$ Ser, $0.179 \pm 0.012$; and Ala, $0.332 \pm 0.037$. 
ponent of ACHC uptake into brain. The nonsaturable component may reflect passive diffusion of $\mathrm{ACHC}$ across the capillary cell membrane. Amino acids are known to cross lipid bilayers by passive diffusion (Klein et al., 1971) and the $K_{\mathrm{D}}$ for ACHC $\left(1.0-1.6 \times 10^{-4} \mathrm{ml} / \mathrm{s} / \mathrm{g}\right)$ approximates the value predicted for passive diffusion across the blood-brain barrier (Rapoport et al., 1979; Yunger and Cramer, 1981; Takasato et al., 1984). Alternatively, the $K_{\mathbf{D}}$ may reflect the presence of a low-affinity (high $K_{\mathrm{m}}$ ) transport system (Weissbach et al., 1982) or may arise as an artifact of measurement of $J_{\text {in }}$ under nonsteady-state conditions (Cunningham et al., 1986) or from consistent underestimation of tracer in the brain vasculature. This last possibility is significant because $q_{\mathrm{br}}^{*}$ was not corrected for $\left[{ }^{14} \mathrm{C}\right] \mathrm{ACHC}$ in the brain endothelial compartment. Under most condition such a correction is not required because the volume of the brain capillary endothelium is very small ( $\sim 0.001 \mathrm{ml} / \mathrm{g}$, Gjedde and Christensen, 1984) and thus would be expected to contribute minimally to brain tracer content. However, at high perfusate ACHC concentrations $(>1 \mu \mathrm{mol} / \mathrm{ml})$, little $\left[{ }^{14} \mathrm{C}\right]-$ $\mathrm{ACHC}$ enters brain and therefore tracer in the endothelial compartment may comprise a significant fraction of the total. For example, it can be estimated that failure to correct $q_{\mathrm{br}}^{*}$ for endothelial tracer will result in a $25 \%$ overestimate in $J_{\text {in }}$ at a perfusate concentration of $10 \mu \mathrm{mol} / \mathrm{ml} \mathrm{ACHC}$. At lower concentrations $(\leq 1 \mu \mathrm{mol} / \mathrm{ml})$, the error would be $<5 \%$. These calculations assume an endothelial cell volume of 0.001 $\mathrm{ml} / \mathrm{g}$ and equal concentrations of $\left[{ }^{14} \mathrm{C}\right] \mathrm{ACHC}$ in perfusate and endothelial cell (Gjedde and Christensen, 1984). Regardless of the cause or mechanism, the "nonsaturable" component contributes minimally $(\sim 7 \%)$ to influx at normal plasma NAA concentrations and therefore in most situations can be ignored. Its presence apparently does not lead to significant errors in calculated $V_{\max }$ or $K_{\mathrm{m}}$, as evidenced by the close agreement between the values obtained using the entire data set $(0-10 \mu \mathrm{mol} / \mathrm{ml})$ and the values obtained using only the influx data at low ACHC concentrations $(\leq 1 \mu \mathrm{mol} / \mathrm{ml})$, where the contribution of the nonsaturable component is negligible.

Finally, the transport constants $\left(V_{\max }, K_{\mathrm{m}}, K_{\mathrm{D}}\right)$, in addition to providing information on the mechanisms of NAA transport into brain, allow prediction of in vivo influx rates for any given set of plasma NAA concentrations. Previous studies have demonstrated that for anesthetized rats predicted influx rates agree with measured rates within a factor of approximately two (Pardridge, 1983; Smith et al., 1987). However, in those studies, the predicted influx rates were not calculated using the exact plasma NAA concentrations from the animals that were used to determine influx experimentally. Since plasma NAA concentrations vary from animal to animal, some difference between measured and predicted rates might be expected. In this study, we demonstrate that agreement between predicted and measured influx rates is actually much better than twofold when plasma NAA concentrations are measured in the same animals as are used to determine influx. The predicted values came within $5-30 \%$ of measured values and the small differences were not statistically significant. The close agreement lends support to the transport model and suggests that the transport constants can be used to obtain accurate estimates of influx in healthy, pentobarbital-anesthetized rats. Since pentobarbital anesthesia produces only small changes in brain NAA uptake (Hawkins et al., 1982), it is likely that the kinetic constants can also be used to obtain reasonable estimates of influx in normal, awake rats.

In conclusion, $\left[{ }^{14} \mathrm{C}\right] \mathrm{ACHC}$ should prove useful as an in vivo probe of NAA transport between plasma and the CNS. It allows accurate in vivo measurements of influx without errors due to tracer metabolism or incorporation into proteins. In addition, it may allow determination of brain NAA concentration and NAA efflux from brain. $\left[{ }^{14} \mathrm{C}\right] \mathrm{ACHC}$ is well suited for use with quantitative autoradiography, which measures regional brain radioactivity but provides no information on the chemical form of the tracer. Furthermore, if labeled with a positron emitting radionuclide, $\mathrm{ACHC}$ could be used to examine amino acid transport in patients with diseases such as phenylketonuria (Washburn et al., 1982).

Acknowledgment: This article is based on work supported in part by Contract No. DE-AC05-760R00033 between the U.S. Department of Energy and Oak Ridge Associated Universities. Experiments were performed in accordance with the Guide for the Care and Use of Laboratory Animals (NIH Publication No. 85-23).

\section{REFERENCES}

Bergstrom M., Ericson K., Hagenfeldt L., Mosskin M., Von Holst H., Noren G., Eriksson L., Ehrin E., and Johnstroem P. (1987) PET study of methionine accumulation in glioma and normal brain tissue: competition with branched chain amino acids. $J$. Comp. Assist. Tomogr. 11, 208-213.

Christensen H. N. (1973) On the development of amino acid transport systems. Fed. Proc. 32, 19-28.

Christensen H. N. and Jones J. C. (1962) Amino acid transport models: renal resorption and resistance to metabolic attack. $J$. Biol. Chem. 237, 1203-1206.

Comar D., Saudubray J. M., Duthilheul A., Delforge J., Maziere M., Berger G., Charpenter C, and Todd-Popropek A. (1981) Brain uptake of 11-C-L-methionine in phenylketonuria. Eur. J. Pediatr. 136, 13-19.

Connors T. A. and Ross W. C. J. (1960) Some derivatives of 1 aminocyclopentanecarboxylic acid and related compounds. $J$. Chem. Soc. 2119-2132.

Cunningham V. J., Hargreaves R. J., Pelling D., and Moorhouse S. R. (1986) Regional blood-brain glucose transfer in the rat: a novel double-membrane kinetic analysis. J. Cereb. Blood Flow Metab. 6, 305-314.

DeFeudis F. V. (1986) The brain is protected from nutrient excess. Life Sci. 40, 1-9.

Gjedde A. and Christensen O. (1984) Estimates of MichaelisMenten constants for the two membranes of the brain endothelium. J. Cereb. Blood Flow Metab. 4, 241-249. 
Hawkins R. A., Mans A. M., and Biebuyck J. F. (1982) Amino acid supply to individual cerebral structures in awake and anesthetized rats. Am. J. Physiol. 242, E1-E11.

Hayes R. L., Washburn L. C., Wieland B. W., Sun T. T.. Anon J. B., Butler T. A., and Callahan A. P. (1978) Synthesis and purification of "C-carboxyl-labeled amino acids. Int. J. Appl. Radiat. Isot. 29, 186-187.

Klein R. A., Moore M. J., and Smith M. W. (1971) Selective diffusion of neutral amino acids across lipid bilayers. Biochim. Biophys. Acta 233, 420-433.

Leo A., Hansch C., and Elkins D. (1971) Partition coefficients and their uses. Chem. Rev. 71, 525-616.

Mans A. M., Biebuyck J. F., Shelly K., and Hawkins R. A. (1982) Regional blood-brain barrier permeability to amino acids after portacaval anastomosis. $J$. Neurochem. 38, 705-717.

Miller G. R. (1966) Simultaneous Statistical Inference, pp. 76-81. McGraw-Hill, New York.

Momma S., Aoyagi M., Rapoport S. I., and Smith Q. R. (1987) Phenylalanine transport across the blood-brain barrier as studied with the in situ brain perfusion technique. J. Neurochem. 48, 1291-1300.

Oldendorf W. H. (1971) Brain uptake of radiolabeled amino acids, amines, and hexoses after arterial injection. Am. J. Physiol. 221, 1629-1639.

Oldendorf W. H. and Szabo J. (1976) Amino acid assignment to one of three blood-brain barrier amino acid carriers. Am. J. Physiol. 230, 94-98.

Oxender D. L. and Christensen H. N. (1963) Distinct mediating systems for the transport of neutral amino acids by the Ehrlich cell. J. Biol. Chem. 238, 3686-3699.

Pardridge W. M. (1977) Kinetics of competitive inhibition of neutral amino acid transport across the blood-brain barrier. $J$. Neurochem. 28, 103-108.

Pardridge W. M. (1983) Brain metabolism: a perspective from the blood-brain barrier. Physiol. Rev. 63, 1481-1535.

Pardridge W. M. and Oldendorf W. H. (1975) Kinetic analysis of blood-brain barrier transport of amino acids. Biochim. Biophys. Acta 401, 128-136.

Phelps M. E., Barrio J. R., Huang S. C., Keen R. E., Chugani H., and Mazziotta J. C. (1985) Measurement of cerebral protein synthesis in man with positron computerized tomography: model, assumptions, and preliminary results, in The Metabo- lism of the Human Brain Studied with Positron Emission Tomography (Greitz T., Ingvar D. H., and Widen L., eds), pp. 215-232. Raven Press, New York.

Rapoport S. I., Ohno K., and Pettigrew K. D. (1979) Drug entry into the brain. Brain Res. 172, 354-359.

Smith Q. R. and Takasato Y. (1986) Kinetics of amino acid transport at the blood-brain barrier studied using an in situ brain perfusion technique. Ann. NY Acad. Sci. 481, 186-201.

Smith Q. R., Takasato Y., Sweeney D. J., and Rapoport S. I. (1985) Regional cerebrovascular transport of leucine as measured with the in situ brain perfusion technique. J. Cereb. Blood Flow Metab. 5, 300-311.

Smith Q. R., Momma S., Aoyagi M., and Rapoport S. I. (1987) Kinetics of neutral amino acid transport across the bloodbrain barrier. $J$. Neurochem. 49, 1651-1658.

Takasato Y., Rapoport S. I., and Smith Q. R. (1984) An in situ brain perfusion technique to study cerebrovascular transport in the rat. Am. J. Physiol. 247, H484-H493.

Wade L. A. and Katzman R. (1975) Synthetic amino acids and the nature of L-dopa transport at the blood-brain barrier. $\mathrm{J}$. Neurochem. 25, 837-842.

Washburn L. C., Sun T. T., Byrd B. L., Hayes R. L., Butler T. A., and Callahan A. P. (1979) High-level production of C-1 1-carboxyl-labeled amino acids, in Radiopharmaceuticals $I I, \mathrm{pp}$. 767-776. Society for Nuclear Medicine, New York.

Washburn L. C., Ringenberg R. E., Sun T. T., and Hayes R. L. (1981) ${ }^{11} \mathrm{C}$-Labeled 1 -aminocyclohexanecarboxylic acid $\left({ }^{11} \mathrm{C}\right.$ $\mathrm{ACHC}$ ), a potential agent for studies of amino acid transport in the brain. J. Label. Comp. Radiopharm. 18, 13-14.

Washburn L. C., Sun T. T., Byrd B. L., Rafter J. J., Hayes R. L., Frey K. A., and Agranoff B. W. (1982) ${ }^{11} \mathrm{C}-\mathrm{ACHC}$, a potential agent for positron tomographic measurement of brain amino acid transport, in Nuclear Medicine and Biology, Vol. I Raynaud C., ed), pp. 642-645. Pergamon Press, Paris.

Weissbach L., Handlogten M. E., Christensen H. N., and Kilberg M. S. (1982) Evidence for two $\mathrm{Na}^{+}$-independent neutral amino acid transport systems in primary cultures of rat hepatocytes. J. Biol. Chem. 257, 12006-12011.

Yunger L. M. and Cramer R. D. (1981) Measurement and correlation of partition coefficients of polar amino acids. Mol. Pharmacol. 20, 602-608. 